\title{
La familia como enemigo: imágenes que los futuros titulados en maestro de primaria de una universidad pública de Madrid poseen sobre la relación familia-escuela en un contexto multicultural ${ }^{*}$
}

\author{
The family as an enemy: images that students of elementary school \\ teacher training of a Public University from Madrid have about the \\ family-school relationship in a multicultural context
}

\author{
Héctor Cárcamo Vásquez ${ }^{* *}$ \\ Departamento de Ciencias Sociales, Universidad del Bío Bío, Chillán, Chile
}

Recibido: 15 diciembre de 2013. Aprobado: 9 de octubre de 2015.

\begin{abstract}
Resumen
El objetivo de este artículo es reconocer las imágenes que los futuros titulados en maestro de educación primaria se forjan acerca de la relación familia-escuela, así como a los roles y las funciones que asignan a la familia en materia educativa, poniendo el acento en las familias migradas internacionalmente. Para estos efectos, se utiliza el enfoque etnográfico, para la recogida de datos se realizaron entrevistas a estudiantes que cursan su formación inicial docente y observaciones en aulas en las que dicha formación tiene lugar. Como resultados tenemos que la relación que piensan que tendrán con las familias se modela desde una perspectiva escolar, es decir que, quienes determinan el tipo, la forma, las instancias y los momentos de la relación son los maestros y los directivos de los centros escolares y que las familias, especialmente aquellas familias migradas, son agentes disruptivos en la dinámica cultural de la escuela; finalmente, se puede sostener que es la propia formación inicial la que fortalece estas imágenes.
\end{abstract}

Palabras claves: familia, escuela, formación inicial docente.

Investigación patrocinada por MECESUP y la Universidad del Bío Bío a través del proyecto UBB 0704 .

Magíster en Investigación Social y Desarrollo por la Universidad de Concepción. Doctor en Antropología Social por la Universidad Complutense de Madrid. Correo electrónico: hcarcamo@ubiobio.cl 


\begin{abstract}
The purpose of this article is to identify the images that the future teachers of elementary school construct about the family-school relationship besides the roles and functions that assign to the family in the educational aspect, with the emphasis placed on the families migrated from abroad. The ethnographic approach is used for these purposes. Some interviews to students in the initial teaching training were carried out for the collection of data, in addition to observation of some classes of the respective program. As a result, we have that the relationship they think they will have with the families is created from a school perspective, that is, those who determine the type, the form, the instances and the moments of the relationship are the teachers and the heads of the school centers and that the families, especially those the migrated from abroad, are disruptive agents in the cultural dynamics of the school. Finally, it may be stated that it is the initial training itself the one that strengthens these images.
\end{abstract}

Keywords: family, school, initial teachers training.

\title{
Introducción
}

España y -para referirnos al área específica de estudio- Madrid, se ha transformado en los últimos años en una ciudad en la que la diversidad cultural se ha hecho evidente. A partir de 1990 y especialmente en los primeros años de este siglo, Madrid se ha transformado en una ciudad receptora de población extranjera, situación que puede explicarse -aunque no únicamente- por la bonanza económica que experimentó el país y esta comunidad en particular. De acuerdo a datos de la Consejería de Asuntos Sociales de la comunidad de Madrid, para el 2013, el 14,9\% de la población corresponde a población extranjera, de las cuales el $14,95 \%$ corresponde al grupo menor de 16 años (personas en edad escolar). El punto más alto de la inmigración se alcanzó en 2010 con un total de 1.118.991 de personas. Hoy se ha experimentado un descenso de la población -explicación que podría encontrarse en la crisis económica por la que atraviesa España-, alcanzado 1.000 .108 personas en 2013 , de los cuales el 29,17\% corresponde a población latinoamericana.

Este flujo migratorio tiene repercusiones en la escuela, tal como lo plantean diversos autores entre los que destacan Osuna (2012), Moscoso (2009), Poveda, Jociles y 
Franzé (2009), Gil (2009), García, Rubio y Bouachra (2008), Franzé (2001), entre otros. Así por ejemplo se observa una concentración de población inmigrante en los centros escolares pertenecientes a la red pública y la consecuente elaboración de estrategias para su recepción. Un ejemplo lo encontramos en las Aula de Enlace, iniciativa que no hace sino sostenerse desde la concepción del déficit cultural produciendo y reproduciendo segregación (Cucalón, 2012). Esta forma de atender al nuevo alumnado repercute también en las formas de entenderlos a ellos y sus familias como agentes potencialmente disruptivos de la dinámica escolar. De modo tal que las estrategias de relación que se articulan desde la escuela operan sobre la base de imágenes estereotipadas en las que persiste la idea de que estas familias se distancian de la cultura receptora y más particularmente de la cultura escolar. Estos y otros elementos de la relación familia-escuela son los que se abordan en los epígrafes siguientes.

\section{Acerca de las familias y su relación con la escuela}

No cabe duda de la importancia que se ha otorgado al papel desempeñado por la familia y por la escuela en los procesos de socialización de los niños/as, estableciéndose tempranamente una diferenciación entre ambas instituciones de acuerdo al peso que se considera que cada una de ellas tiene en la socialización de los niños/as según la edad o etapa vital de éstos/as. Garreta (2009), Cerletti (2010), Neufeld (2000), entre otros, dan cuenta de la necesidad de articular el análisis desde una lógica de continuidad entre los agentes, evidenciando la necesidad de configurar una relación familia-escuela dialógica, fluida, estable y comprometida, sobre todo producto del incremento de alumnos extranjeros en aulas de escuelas públicas. Las reformas educativas desarrolladas en España, en especial, a partir de 1990 con la Ley de Ordenamiento General del Sistema Educativo (LOGSE) han hecho eco de esta situación y han ido armando poco a poco el marco normativo que regula actualmente diversos aspectos de la mencionada relación. Ahora bien, la normativa es letra muerta si no cuenta con la convicción y la adhesión del profesorado, de ahí la importancia de estudiar cómo se trabaja asimismo esta temática en el proceso de formación inicial docente.

De acuerdo a Garreta (2009), las expectativas que las familias depositan en la educación intervienen directamente en el tipo de relación que establecen con la escuela. No obstante lo anterior, el grado de compromiso e implicación de las familias no depende exclusivamente del interés que éstas tengan en comprometerse e implicarse, sino también de la actitud que el profesorado adopte con respecto a dicho compromiso e implicación. 
En consecuencia, las imágenes que los estudiantes de magisterio de primaria (para centrarse ya en el colectivo que constituye el universo de esta investigación) se forjen de las familias y del modo en que éstas se relacionan con la escuela tendrán una gran importancia para entender cómo se van a relacionar en el futuro con ellas, es decir, cuando ejerzan profesionalmente como maestros, puesto que -como afirman diversos autores (Gubbins, 2012; Garreta, 2008; Roldán, 2008; Pereda, 2006; Santín, 2006)- el tipo de relación que se establece entre las familia y la escuela está mediada, en términos generales, por las teorías implícitas y/o explícitas que los profesores manejan al respecto. Es más, autores como Santos Guerra (2010), Feito (2010), Garreta (2008), sostienen que para asegurar la participación de las familias y una buena relación con ellas, hay que comenzar interviniendo en la formación inicial del profesorado, ya que suelen tener una imagen negativa del rol educativo de los padres, a la vez que reclaman espacios para desempeñar su profesión. Como veremos en el apartado de resultados, los futuros maestros de primaria tienden a externalizar (a situar fuera de la escuela) la responsabilidad del bajo rendimiento académico de los alumnos (Jociles, Franzé y Poveda, 2012), de forma que se responsabiliza a las familias cuando este rendimiento es bajo, pero el alto rendimiento es atribuido, por el contrario, al buen hacer del profesorado y/o a la buena gestión de los centros escolares; apreciándose una cierta coincidencia con los planteamientos de Río (2010), quien afirma que el discurso de los profesores oscila entre dos tipos de juicios; por una parte el que mantiene que las familias no saben y no pueden intervenir de manera adecuada en la educación escolar de sus hijos; y otro que les recrimina que no quieren saber hacerlo. En cualquier caso, ambos tipos de juicio son elaboraciones discursivas de los profesores que hacen referencia a la falta de capacidad y/o la falta la voluntad de las familias para ajustarse a la norma escolar, máxime cuando de familias inmigradas se trata, pues se parte de la idea de que los sistemas educativos de origen son deficitarios.

Muchas de las imágenes que los futuros maestros de primaria tienen con respecto a las familias se configuran sobre la base de la importancia que se otorga a éstas como principales agentes educadores en los primeros años de vida de una persona. Es tal la relevancia que a este respecto se les da en la literatura especializada (tanto psicológica, como psicopedagógica, sociológica o socioantropológica, por ejemplo) que no resulta extraño que los estudiantes de magisterio les atribuyan la responsabilidad de los problemas que presentan sus hijos, ya sea en el plano de la convivencia escolar y/o en el rendimiento académico que se prevé que lleva al fracaso. Es más, esta externalización de responsabilidades, para seguir con la terminología usada más atrás, se apoya precisamente en la construcción discursiva de un ideal de padres o, si se quiere, de unos padres ideales ${ }^{1}$ lle-

1 El padre/madre ideal desde esta perspectiva es aquel que se compromete con la educación de sus hijos; dicho compromiso se ve representado, fundamentalmente, por la asistencia a tutorías individuales, la asistencia a 
vada a cabo a partir del discurso tecnocrático que prima en el sistema educativo, es decir, desde los requerimientos de la escuela, que les asigna un rol y, por tanto, unas funciones ajustadas a sus necesidades y a su forma de concebir el mundo. En suma, el profesorado $\mathrm{o}$, en este caso, los futuros titulados en maestros de primaria esperan que el rol que cumplan los padres, con respecto a la escuela, se restrinja a los ámbitos predefinidos desde ella. Es un rol, por tanto, que si se conceptúa como un espacio de participación en la escuela, puede ser entendido al modo de los invited spaces de los que hablan, por ejemplo, Gaventa (2005) y Cornwall (2002), es decir, de los espacios creados desde arriba, en este caso por la escuela, para que sean llenados por las familias. Siguiendo el planteamiento de Bolívar (2006), podríamos sostener que el rol al que se refieren los futuros maestros se modela a partir de una idea de profesionalidad clásica en la que prima la desconfianza respecto a la participación de los padres por considerarlos no capacitados para la tarea de enseñar; de modo tal que, subyace un distanciamiento entre maestros y padres que impide la colaboración entre los agentes.

Volvamos a la externalización de responsabilidades que se detecta en sus discursos cuando elaboran explicaciones de los problemas escolares que aquellos puedan presentar; esto se hace más patente cuando consideran el aumento de familias migradas. La presencia de familias migradas supone un desafío adicional para los docentes de educación primaria $y$, aunque de un modo distinto, también para quienes se preparan para serlo, pues estas familias experimentan dificultades específicas en su relación con la escuela. Una de ellas consiste en que a menudo no dominan el idioma del país receptor, lo que dificulta el establecimiento de relaciones fluidas con el centro escolar. Otra dificultad se deriva de las experiencias escolares de los padres y, en muchos casos, de los propios niños en sus primeros años de escolarización, ya que han tenido lugar en sistemas educativos diferentes al español, lo que puede contribuir a dificultar, al menos inicialmente, el establecimiento del tipo de relaciones mencionado más arriba. Y una tercera dificultad se da como consecuencia de las diferencias culturales, en lo que se refiere concretamente a lo que cada quien entiende por educación, al valor que a ésta le da y a las expectativas, mediadas en este caso por la percepción e interpretación de las mencionadas diferencias culturales, que la escuela y los docentes tienen con respecto a las familias y éstas tienen con respecto a la escuela y los docentes. En el caso de algunos de los estudiantes de magisterio entrevistados, la presencia de familias migradas en el sistema educativo español representa una preocupación que es abordada, en sus discursos, mediante llamadas de atención sobre la necesidad de atender a la diversidad del alumnado. No obstante, tal

reuniones convocadas por el profesor/a, el apoyo en la realización de deberes para ser trabajados en casa, entre otros. Aunque este último aspecto no puede ser observado por el maestro, es cotejado mediante la revisión de los deberes que cada niño lleva al colegio. 
como plantea Garreta, "las opiniones sobre las buenas o malas relaciones entre la escuela y la familia se construyen a partir de unos parámetros que reflejan lo que se considera un funcionamiento correcto y deseable" (2009, p. 276).

Marina (2006) pone en evidencia la necesidad de trabajar la relación familia-escuela en los procesos de formación inicial del profesorado debido a que el papel de las familias es crucial para el buen desarrollo educativo de los niños. De acuerdo a este autor, la atención que se presta en España a esta temática es escasa, a pesar de que es indispensable contar con un profesorado que no sólo tenga dominio de los temas que se abordan en el currículum o de las didácticas que le facilitan su acción pedagógica, sino también capacidad de análisis y reflexión crítica que le permitan reconocer su labor educativa en el más amplio sentido de la palabra, lo que incluye saber relacionarse de manera adecuada con las familias. A esto último, sin embargo, apenas se le reserva espacio en la formación inicial del profesorado cuando la adquisición de ese saber no es una cuestión simple y cuando, además, no todo depende de la voluntad del profesorado, sino que éste debe tomar en consideración (y, por tanto, conocer y/o aprender a identificar) los múltiples y multifacéticos factores que inciden en la relación que estamos considerando; factores como, por ejemplo, el grado de cercanía que las familias tienen con respecto a la cultura escolar. De ahí la relevancia de tratar esta temática, ya en la formación inicial del profesorado, desde una perspectiva crítica y reflexiva.

\section{Método y técnicas}

El diseño de investigación se sustentó en la metodología cualitativa con enfoque etnográfico. El trabajo de campo se realizó en la ciudad de Madrid entre los años 2010 e inicios de 2013. Se trabajó en dos universidades públicas y dos privadas. El proceso de producción de información se llevó a cabo mediante la técnica de entrevistas de tipo etnográfico a futuros titulados en maestro de educación primaria. Se efectuó un total de 32 entrevistas ( 22 mujeres y 10 hombres). Para el acceso a los informantes se utilizó la técnica de bola de nieve e informantes claves. El número de entrevistas estuvo determinado por el punto de saturación discursiva, el cual se alcanzó en la entrevista número 29, sin embargo, con la finalidad de prevenir potenciales sesgos se procedió a la realización de tres nuevas entrevistas. En cuanto a los criterios de inclusión de los sujetos diremos que nos interesó el que hubiesen superado el primer año de su formación y que fuesen estudiantes matriculados al momento de realizar las entrevistas. El análisis de los discursos se efectuó tomando como base el paradigma de codificación propuesto en la teoría funda- 
mentada. Otra de las técnicas utilizadas corresponde a la observación. Uno de los aspectos que caracteriza el enfoque etnográfico es la presencia inmediata del investigador en el campo, motivo por el cual la observación es de gran relevancia. Siguiendo lo planteado por Jociles (2002), diremos que las observaciones realizadas podrían catalogarse como pasivas y moderadas, modalidades que se fueron adoptando en función de momentos y circunstancias concretas.

Tabla 1.

Características de la muestra de futuros maestros entrevistados

\begin{tabular}{cccccc}
\hline & \multicolumn{2}{c}{ Universidad pública } & \multicolumn{2}{c}{ Universidad privada } & \\
\cline { 2 - 5 } Edad & Hombre & Mujer & Hombre & Mujer & Total \\
\hline 20-25 años & 7 & 5 & 2 & 8 & 22 \\
25-30 años & 1 & 2 & 0 & 3 & 6 \\
30-35 años & 0 & 1 & 0 & 2 & 3 \\
35-40 años & 0 & 0 & 0 & 0 & 0 \\
40-45 años & 0 & 0 & 0 & 0 & 0 \\
45-50 años & 0 & 0 & 0 & 1 & 1 \\
Total & 8 & 8 & 2 & 14 & 32 \\
\hline
\end{tabular}

Fuente: Elaboración propia.

Las observaciones se realizaron en dos aulas universitarias en las que se desarrolló la asignatura de Educar para la igualdad y la ciudadanía, asignatura que forma parte de la malla curricular del grado de Educación Primaria de una de las universidades públicas estudiadas, y cuya duración es de carácter cuatrimestral. La intención inicial fue realizar únicamente observaciones pasivas con el fin de captar la forma en que se desarrollaban las clases, tomando en consideración elementos como el discurso docente, las metodologías utilizadas, las referencias bibliográficas hechas en el aula, la disposición espacial del estudiantado en ella, así como la participación y el discurso de éste en torno a las temáticas abordadas (familia, escuela, multiculturalismo, interculturalismo, ciudadanía, entre otras). Este tipo de observación tuvo lugar en la mayor parte de las sesiones a las que asistí; no obstante, producto de la propia dinámica de las clases, el tipo de observa- 
ción terminó adoptando la forma de participación moderada. Así, tanto en las clases de Trinidad $^{2}$ como en las de Felipe, aunque de manera distinta, fue la propia dinámica de las situaciones observadas la que modeló el nivel de participación que pude alcanzar. Ello introdujo riqueza en el proceso de investigación, pues permitió que pudiera desplazarme desde las fronteras externas del espacio social estudiado hasta el centro de la dinámica interaccional, pero a la vez me supuso un mayor esfuerzo, en cuanto sujeto que observa, en la medida en que tuve que redoblar la vigilancia epistemológica para no olvidar las exigencias de mi papel como observador.

Los registros que se exponen se corresponden más bien con fragmentos significativos de actos ocurridos en cada uno de los escenarios en los que llevé a cabo la observación. En la presentación de los resultados los registros de las observaciones se expondrán según grupo: grupo 1 (a cargo de Trinidad) y grupo 2 (a cargo de Felipe).

\section{Resultados}

Lo primero que se puede señalar es que el discurso de los futuros titulados en maestros de educación primaria (en adelante alumnos) acerca de las familias y la relación de éstas con la escuela se configura considerando como elemento central el cumplimiento de objetivos escolares, esto es, de los objetivos propios de la escuela. Esta centralidad que adquiere la escuela en las imágenes que los alumnos se forjan de la familia y de la relación que se establece entre ésta y la escuela, se encuentra, entre otros, en el discurso de Jesús:

Si la escuela te enseña a ayudar a una persona anciana a cruzar la acera y la familia te dice lo contrario, hay un problema. Es que se tiene que dar una red de conexiones entre familia y escuela, tienen que estar coordinados en la medida de lo posible, que los padres no vayan al colegio sólo cuando el niño está mal. Ir y no sólo a escuchar las cosas malas, que su hijo ha hecho tal; no, también cuando ha estado bien. Hagámosles sentirse partícipes de esa educación, que ellos se sientan parte de ese colegio y de la educación que se les está dando a los niños. (Jesús, comunicación personal, 20 de diciembre de 2010)

2 Los nombres utilizados para referirse a los "informantes", sean profesores o estudiantes, son pseudónimos orientados a salvaguardar el anonimato de los mismos y la confidencialidad de la información aportada. 
Este fragmento de entrevista permite confirmar una vez más que el punto de vista que los alumnos adoptan cuando hablan de la relación familia-escuela es el de la escuela; un punto de vista a partir del cual la participación de las familias se entiende a menudo, como es el caso de Jesús, como una situación en que "se sientan partícipes" - para usar sus mismas palabras- de la "educación que se les está dando a los niños", por tanto, como un compartir esa educación definida por y para la escuela. Aunque reconocen que "la familia es muy importante también", todo ocurre como si su rol tuviera que estar en sintonía con los lineamientos que emanan de lo escolar. Se puede decir, por consiguiente, que los alumnos asumen que, en el contexto de la conformación de la relación familia-escuela, quien debe llevar la iniciativa y establecer las directrices para ello son los profesores, en tanto que profesionales responsables del proceso educativo en el espacio escolar. Expresan también la necesidad de un trabajo coordinado entre los diferentes agentes sociales; ahora bien, lo hacen pensando siempre en acciones orientadas a la consecución de objetivos que, como se ha dicho, se definen desde la escuela como pertinentes para los niños.

En fin, yo creo que familia y escuela deben ser dos grupos que deben trabajar como complemento, por supuesto que en las casas se debe educar en valores, pero también en la escuela. Familia y escuela deben remar más o menos en la misma dirección, con diferentes puntos didácticos y metodologías pero me parece que es tarea de los dos grupos. (Diego, comunicación personal, 08 de abril de 2011)

Las palabras de Diego permiten ver algunos aspectos que forman parte de las imágenes sobre la familia y sobre la relación familia-escuela que han sido incorporadas por los alumnos. El primero de esos aspectos es la explicitación de la necesidad de un trabajo conjunto entre los distintos agentes sociales, tal como se dijo en el párrafo precedente; lo que es coherente -como lo ponen de manifiesto Garreta $(2009 ; 2008 ; 2007)$, Pereda (2006), Bolívar (2006), Santos Guerra (1997), Epstein (1995) entre otros- con los discursos que se consideran oficiales en este ámbito, como el de la UNESCO, por ejemplo. El segundo aspecto consiste en la asignación a la familia de una función educativa que se sitúa sobre todo en la arena de la formación en valores, en tanto que la transmisión de conocimientos científicos, así como de otros saberes que trasciendan dicha esfera, se plantea como tarea privativa de la escuela y, por tanto, de responsabilidad exclusiva del profesorado.

En este sentido, aunque lo que aparece regularmente en el discurso de los alumnos es la necesidad de establecer consensos entre la familia y la escuela, lo que subyace es más bien el deseo de propiciar la cooperación de la familia para que la escuela pueda alcanzar sus objetivos. Y se trata de una cooperación que, en los discursos aparece expresada 
mediante metáforas como las contenidas en las siguientes frases: "remar en la misma dirección" (Diego, comunicación personal, 08 de abril de 2011), "que no sea una guerra" (Beatriz, comunicación personal, 24 de octubre de 2011), "que no choquen las ideas" (Guadalupe, comunicación personal, 14 de abril de 2011), "ir de la mano" (Adriana, comunicación personal, 03 de noviembre de 2010). De modo tal que en la cotidianeidad de la escuela se va configurando un tipo de relación específica entre ella y la familia a través de momentos, espacios, formas y funciones bien delimitados. Por ejemplo, a las familias se las mantiene informadas del estado de avance del alumno mediante los informes académicos que se entregan trimestralmente; se las convoca para asistir a las reuniones, habitualmente de carácter informativo, que organiza el tutor y se les pide que apoyen la realización de "los deberes escolares" fuera del tiempo y del espacio de la escuela, extendiéndose así el rol de los niños como alumnos hasta el tiempo y el espacio de la familia. Es decir, "remar en la misma dirección" consiste en hacerlo según la dirección establecida por la escuela y "que no choquen las ideas", para mencionar una sola metáfora más, no es otra cosa que limitarse a ser informado y, por tanto, a escuchar lo que la escuela tiene que decir, lo que elimina cualquier posibilidad de que ese choque se dé.

Ahora bien, al fijar la atención en los escenarios de observación, se puede apreciar que en unos contextos en los que se plantea la necesidad de mejorar la educación, se procura concientizar a los alumnos con respecto a los desafíos a los cuales deberán hacer frente una vez iniciada su carrera docente; y entre esos desafíos, se encuentran los cambios tecnológicos, los cambios económicos y, en especial, los cambios en las familias. En el transcurso de las primeras clases de Educar para la igualdad y la ciudadanía, surgieron con frecuencia comentarios e imágenes alusivas al último de los desafíos señalados, es decir, a las familias y a su compromiso (o, más bien, a su falta de compromiso) con la educación de sus hijos e hijas. Se suele hablar de una manera negativa de este agente educativo, atribuyéndole, en especial, un supuesto incumplimiento de los roles parentales que, desde la visión del profesorado, debe cumplir.

\section{Registro 1: Observación con notas de campo. Grupo 1.}

Contexto de las prácticas observadas: En un momento de la clase, la profesora pregunta qué cosas se deben cambiar de la educación actual. La respuesta espontánea de un alumno se refiere al compromiso del profesorado. Luego la profesora continua: ¿qué otras cosas hay que cambiar? Prácticas observadas: A la pregunta formulada por Trinidad nadie responde, se genera un silencio... hasta que Lucía, una chica sentada en 
las primeras filas de la columna de la izquierda, muy cercana a la tarima, dice que es necesario reestablecer las relaciones entre la familia y la escuela, planteando que hay una necesidad mutua. Trinidad dice que es cierto, que debe haber una relación entre los profesores y las familias de los niños, pero... -en ese momento Trinidad hace una pausa $y$, expresando facialmente su disconformidad con el papel de los padres, continúa diciendo- los padres se desentienden de la educación. Y, con tono de disgusto, añade: "Muchas veces fastidian los esfuerzos de los maestros". La clase escucha en silencio, salvo algunos murmullos en las últimas filas de la columna de mesas situada a la izquierda del aula. Trinidad advierte a los alumnos que tendrán que lidiar con los padres, que éstos a menudo se cargan la labor del maestro, que no se comprometen adecuadamente con la educación de sus hijos y que otras veces atacan a los maestros cuando solicitan mayor compromiso con el proceso educativo. (19 de septiembre de 2012)

Se puede decir que en las notas de observación de la clase de Trinidad reproducidas hace un momento, se recoge una muestra del discurso sobre los padres de alumnos que circula en la formación inicial del profesorado. De lo observado en el aula, pueden destacarse algunas constataciones. La primera es que, en el marco de la formación inicial docente, se instalan prejuicios en los alumnos acerca de la relación familia-escuela. La segunda apunta a que el aula es un espacio que contribuye a configurar la idea de que las familias no cumplen adecuadamente el rol que desde la escuela se les confiere. Y la tercera consiste en que esto último coadyuva a modelar una imagen quebrada de la relación familia-escuela, de cuyo quiebre se responsabiliza a las familias. ¿Cómo es que se afirma, ante los alumnos del grado de magisterio en educación primaria, que los padres frustran ("fastidian" decía Trinidad) los esfuerzos de los maestros? ¿y cómo se fundamenta esta idea? Según se desprende del material etnográfico producido, se trata de una idea sobre la que apenas se profundiza, sino que se lanza sin más, es decir, como si no precisara de mayor argumentación ni de apoyo en datos científicamente contrastados.

Por otro lado, en las imágenes sobre las familias que elaboran los alumnos, pueden ser identificados otros aspectos que, en su conjunto, muestran una idealización de las familias del pasado en lo que se refiere tanto a la función que cumplían en la formación en valores de los niños como al tipo de relación que establecían con la escuela. Los dos principales rasgos que se usan para caracterizar esta relación son el respeto a la autoridad del maestro y la no intromisión en los asuntos de la escuela y, por tanto, en los asuntos que se consideran propios y exclusivos de él. A modo de ejemplo, se presenta a continuación un fragmento de la entrevista realizada a Carlota, que evidencia la importancia que se otorga a la familia como formadora en valores, expresados en este caso a través del respeto. 
La familia es fundamental, porque si la familia no te enseña respeto, da lo mismo que la escuela te lo enseñe, porque la familia, para mí, es el modelo fundamental, por lo menos cuando eres niño. Cuando creces vas viendo las cosas desde tu propio punto de vista, pero igual te va a afectar mucho lo que hayas aprendido antes, porque te va a quedar ahí, porque el desaprender cosas que hayas aprendido antes, cuando niño, es bastante difícil. (Carlota, comunicación personal, 13 de abril de 2011)

A la vez que reconocen que la familia tiene un gran peso en la formación en valores, desconfían de que las familias actuales cumplan adecuadamente esta función, a diferencia de lo que ocurría con las de antes que, según piensan, dedicaban más tiempo a ello. Con todo, los alumnos no extraen de esto que la escuela deba responsabilizarse de la formación en este área, sino más bien que debe constituirse en agente facilitador para que las familias puedan cumplir de nuevo esa función. Esto es lo que propone Talía:

El problema es que las familias han perdido el tiempo que se dedicaba a formar en esos temas. Ahora mismo en España los dos padres tienen que trabajar, hay que dedicarle un tiempo muy grande al trabajo. Entonces, los niños pasan más tiempo en la escuela del que pasábamos nosotros, y también es verdad que pasan menos tiempos con otros iguales. Cuando el niño llega a casa está solo con la tele o con el ordenador. Antes la familia cumplía esa función. ¿Que ahora la tarea de la escuela es hacer lo que no hace la familia? No, la escuela no está para hacer lo que la familia no hace. La familia tiene que reflexionar, pero sí que la escuela está para ayudar para que esas familias lo hagan. (Talía, comunicación personal, 24 de agosto de 2011)

Una idea bastante recurrente en el discurso de los alumnos, que emerge de la contraposición entre las familias de hoy en día y las familias de antes, consiste -de este modoen que las familias incumplen el rol que les corresponde en la educación ético-valórica de los hijos, lo que se ve plasmado en un exceso de permisividad, en una despreocupación por la responsabilidad personal y en un no-reconocimiento de la autoridad. Esta imagen sobre la familia puede obedecer al hecho de que hayan vivido una brecha generacional en el seno de sus propias familias, ya que a partir de los años 80 -como han reconocido, entre otros, Garreta (2009), Fernández (2007), Martín y Coll (2003), Marchesi (2000) o Pozo (1996)- comienza a experimentarse en España profundos cambios en la sociedad, en general, y en las familias en particular, a través del incremento de la inmigración entre 1990-2010. Algunos de los cambios se manifiestan en las formas que adoptan los adultos para relacionarse con los niños y los jóvenes, así como en las dinámicas familiares que surgen como consecuencia de las transformaciones del mercado laboral y de la pérdida del monopolio de la información por parte de los adultos. Los roles que los alumnos 
atribuyen a las familias en materia educativa se sitúan en el ámbito de la formación éticovalórica, asumen que la transmisión/adquisición de saberes teórico-conceptuales o, si se quiere, científicos es tarea privativa de la escuela y, en consecuencia, la familia debe actuar sólo como colaboradora, a diferencia de lo que piensan acerca de la formación en valores, con respecto a la cual reconocen la importancia de la familia y la necesidad de que haya complementariedad entre ésta y la escuela.

En la actualidad los padres culpan a los profesores de que sus hijos no consiguen las metas que ellos se han planteado, y no han sido capaces de enseñárselo. Y para no asumir su culpa siempre es mejor echársela a otros. La educación entre personas se enseña desde que naces y de manera progresiva a lo largo de toda la vida. (Diana, comunicación personal, 11 de noviembre de 2010)

Las funciones que los alumnos atribuyen a las familias son las mismas independientemente de que se trate de las familias de ahora o de las familias de antes, autóctonas o migradas; sin embargo, a la vez está bastante extendida entre ellos la idea de que las familias de ahora -como se ha indicado- no cumplen esas funciones, lo que tiene como consecuencia que la escuela tenga que asumir nuevas responsabilidades.

Yo, por lo que he estado viendo, es que los niños se ponen a gritar, los niños hacen lo que les da la gana y (los padres) no les dicen nada. Tal vez me lo estoy inventando, pero (pienso que los padres) dirán: "Yo no soy capaz de castigar a mi hijo y en la escuela sí lo hacen". Entonces, creo que eso les genera un poco de frustración. (Beatriz, comunicación personal, 24 de octubre de 2011)

A modo de complemento podemos presentar el siguiente registro:

\section{Registro 2: Observación con notas de campo. Grupo 1.}

Contexto de las prácticas observadas: La profesora trabaja la presentación del texto "El valor de educar" de Savater y, cuando llega al capítulo "El eclipse de la familia", insiste en proyectar una imagen de la familia que no se compromete con el proceso educativo de sus hijos de forma adecuada. Prácticas observadas: Trinidad está sentada en la silla ubicada detrás de la mesa que está en la tarima, lee sus fichas, hace una pausa y -con voz enérgica- plantea que los padres no están comprometidos con el trabajo del profe- 
sorado, se pone de pie y -siempre desde la tarima- se dirige al extremo más cercano a las ventanas del aula y dice, con expresión de asombro, que el profesor muchas veces está solo, que muchas veces los padres van al centro sólo a exigir explicaciones al profesor. La clase escucha y Trinidad recalca: “¿acaso no habéis sabido de agresiones de padres a profesores?”. (26 de septiembre de 2012)

Situaciones como la presentada en la anterior cita etnográfica pueden ser consideradas como una de las fuentes que contribuyen a la formación, en los alumnos de magisterio en educación primaria, de una imagen de las familias actuales como obstáculos para el buen desarrollo de la acción docente y, a veces, incluso como saboteadoras de la misma. Más aun cuando dicha imagen se proyecta insistentemente.

\section{Registro 3: Observación con notas de campo. Grupo 1.}

Contexto de las prácticas observadas: La profesora da por culminado el texto de Savater y comienza con el de Victoria Camps que se titula "Creer en la educación". Hace una pequeña introducción al texto y luego pasa al capítulo "La familia ha abdicado". Prácticas observadas: La profesora dice a la clase con tono enfático: “¡Veis lo que digo! No sólo Savater, también Camps lo plantea en su libro". Trinidad insiste en la idea de que las familias no se responsabilizan de la educación de sus hijos. Arantxa, sentada en el centro del aula junto al pasillo que da a la puerta, dice que hay que pensar que muchas veces papá y mamá trabajan, y la profesora responde que es así, pero no está hablando de los motivos, sino del hecho de que están ausentes. (27 de septiembre de 2012)

Como se aprecia en los registros 2 y 3 , se vuelve a exponer una imagen minusvalorativa de las familias actuales y de su papel en materia educativa de forma estereotipada (Del Olmo, 2005). Cuando estaba realizando esa observación, me pregunté de dónde surge o había surgido esa representación de la profesora. Al mes siguiente, antes de entrar a la clase (la del 24 de octubre), le requerí su opinión sobre las familias y en qué fuentes la apoyaba, y me señaló que sus fuentes principales eran Fernando Savater y Victoria Camps y la propia experiencia que se vive en Madrid con las familias inmigradas. Aunque me indicó también que no estaba de acuerdo con la totalidad de los planteamientos de estos autores, era visible que la representación de las familias como agentes disruptivos que manejan (y difunden) en sus obras había sido incorporada por Trinidad. Ello me lleva a pensar que se corre el riesgo de potenciar, desde la propia formación inicial docente, una imagen de la relación familia-escuela que poco ayuda a transformar la realidad, sobre 
todo si el profesorado de magisterio no recurre a un amplio abanico de fuentes bibliográficas que permita nutrir una mirada también amplia acerca del papel de la familia en materia educativa, como pudieran ser, por ejemplo, los trabajos desarrollados por Río (2010), Feito (2010), Moscoso (2009), Garreta (2009; 2008; 2007), Pereda (2006), Epstein (1995), o entre otros científicos sociales.

Que las familias no se responsabilizan ni se comprometen con la escuela es un supuesto apenas discutido que, con todo, ha pasado a formar parte del discurso predominante en la escuela, desde el cual las familias son representadas siempre del mismo modo. Esto es, incumpliendo sus roles parentales, sin que se problematice esta representación; por ejemplo, previendo las potenciales implicaciones que estas prenociones del profesorado pueden tener para las familias (Pozo, 1996), puesto que puede suceder que las representaciones sociales que los maestros de primaria se hayan forjado sobre las familias condicionen en gran medida el tipo de relación que éstas establezcan con la escuela.

No obstante lo anterior, en ocasiones, los alumnos aluden a los cambios sociales que están repercutiendo en las familias como elementos que pueden ayudar a comprender y a explicar esa desafección a su rol educativo a la que se hace referencia durante el desarrollo de la asignatura. Así queda reflejado en el siguiente fragmento del diario de campo:

\section{Registro 4: Observación con notas de campo. Grupo 1.}

Contexto de las prácticas observadas: Luego de presentar los textos de Savater y Camps, Trinidad retoma los planteamientos de estos autores para exponer lo que considera un problema para el ejercicio de la docencia en educación primaria. Prácticas observadas: Trinidad comienza la clase situada en el pasillo del aula entre la primera y cuarta fila, pide silencio golpeando sus palmas. La profesora decide comenzar y pregunta: “¿Qué pensáis de los textos de Fernando Savater y Victoria Camps?". Se genera un largo silencio. Trinidad -con cara de asombro- pregunta “¿Es que nos pensáis nada?”. Silencio... Trinidad insiste: "Yo quiero que reflexionéis". Con el fin de iniciar el diálogo, la profesora plantea -esta vez desde la tarima- que los niños vienen cada vez más mal educados, lo que atribuye a la deficiente preocupación de las familias. Cruzándose de brazos, pregunta a la clase su opinión al respecto. Laura levanta la mano para pedir el turno de palabra. Está sentada en las primeras filas de la columna del lado izquierdo. Trinidad pide a la clase que escuche a la compañera. Laura dice que es cierto, pero que 
no se puede generalizar, porque algunos no se preocuparán, pero tal vez otros padres no pueden encargarse de sus hijos. Alfredo, un chico sentado en la tercera fila de la columna derecha, apenas Laura acaba de plantear su idea, dice que hoy en día ambos padres trabajan y llegan tarde a casa. Luego María, sentada junto a la puerta al igual que Alfredo, sin pedir el turno de palabra afirma que muchos padres malcrían a sus hijos por el sentimiento de culpa de no estar siempre ahí, con ellos, pero que finalmente quien tiene los problemas en la clase es el profesor. Se escuchan murmullos en diferentes lugares del aula. No puedo distinguir lo que dicen; sin embargo, parece que entre sí conversan sobre el tema planteado, a diferencia de otras ocasiones en que hablan acerca de otras cosas. Trinidad, bajando de la tarima y visiblemente entusiasmada con la participación de los alumnos, pide más opiniones. Así, Roberto, uno de los alumnos que tiene más edad y que habitualmente se sienta casi al finalizar el aula, junto al pasillo de la columna derecha, dice que si los niños vienen con "déficit de buenos modales", difícilmente el profesor puede hacer bien su trabajo, pues estará preocupado por enseñarles a sentarse bien, a respetar a los compañeros cuando hablen... todas cosas que debe enseñar la familia. Esta opinión da pie para que Sandra, sentada en el centro del aula diga, con tono de disconformidad, que finalmente el profesor es el que tiene que encargarse de todo y encima tiene que recibir las críticas de todos. El grupo de compañeras sentadas junto a ella mueve sus cabezas asintiendo. (04 de octubre de 2012)

De este modo, desde la formación inicial docente se crean instancias (a partir, por ejemplo, de ciertas referencias bibliográficas) que fomentan que los estudiantes vayan construyendo una imagen de las familias de los alumnos como potenciales enemigas. Se modela una idea a partir de la cual ven amenazado el buen desempeño de sus funciones como futuros maestros a causa de que las familias no cumplen el papel que se debe esperar de ellas. En suma, piensan que si los maestros fallan en ese desempeño es a consecuencia del incumplimiento de los roles parentales, es decir que externalizan las responsabilidades en el mismo sentido ya visto en páginas anteriores.

Los alumnos plantean la existencia de una tensión entre las familias y los profesores, que se origina en el hecho de que los padres no cumplen adecuadamente el rol que deben desempeñar en la educación de sus hijos. En tal sentido, afirman que los padres no dirigen su acción a apoyar el quehacer de la escuela sino que, por el contrario, a veces llegan a convertirse en agentes disruptivos (más aún cuando de familias inmigradas se trata, por cuanto al distanciamiento con la cultura escolar se suma el distanciamiento con la cultura receptora), puesto que se enfrentan al profesor con la intención o con la excusa de defender a sus hijos. En cuanto a lo que consideran ideal, concuerdan todos en que es necesario establecer relaciones armoniosas entre quienes están más directamente 
involucrados en el proceso educativo de los niños (el profesorado y la familia), pero en la forma en que conciben esas relaciones subyace una imagen de las familias como entes pasivos cuyo aporte a dicho proceso educativo debe limitarse a responder a las demandas realizadas desde el profesorado.

La posibilidad planteada por los alumnos de que las familias no estén cumpliendo su rol de forma adecuada concuerda con lo que afirma Garreta $(2009 ; 2008 ; 2007)$ en el sentido de que, en el currículo de la formación inicial docente que se imparte en las universidades españolas, priman ciertos postulados sociologicistas acerca de las familias, a partir de los cuales éstas son descritas como agentes sociales que, en la actualidad, están sufriendo hondas transformaciones (en su estructura, dinámica, roles de género, relación con el mercado de trabajo, etc.), algunas de los cuales (en particular, la falta de tiempo por trabajar los dos padres y hacerlo, además, en horarios cada vez más prolongados) redundan en un descuido del apoyo escolar a los hijos, y otras en una cierta desafección con respecto a sus funciones en la socialización primaria de los mismos. Ello habría ocasionado que la escuela y, particularmente, los profesores hubieran visto ampliadas y diversificadas las suyas por tener que asumir las que las familias, consciente o inconscientemente, habrían desplazado hacia ella. (Fernández, 2007)

Esta imagen también es posible apreciarla en el contexto del desarrollo de la asignatura:

\section{Registro 5: Observación con notas de campo. Grupo 2.}

Contexto de las prácticas observadas: Como es habitual en la clase, se desarrollan trabajos en grupos. El trabajo consiste en identificar situaciones que ocurren en la escuela con respecto a la familia, la violencia, la participación ciudadana y los derechos de la infancia. Estos temas deberán ser relacionados con las vías a través de las cuales se ponen de manifiesto. Las vías que apunta el profesor son: actitudes del profesorado, mensajes de libros de textos, organización del centro y formas de disciplina. La idea es relacionar un tema con una vía utilizando para ello un ejemplo concreto. Prácticas observadas: El profesor comienza a agrupar a los alumnos. Me integra en uno de los grupos de trabajo. El grupo está compuesto por dos chicas y dos chicos. Llama mi atención el modo como el grupo aborda el tema de la familia. Ricardo, que es quien toma la iniciativa, dice que sería adecuado vincular este tema con la disciplina. Sin que nadie se lo indique, Luis comienza a tomar notas de lo dicho por Ricardo. Leticia 
y Doris asienten en silencio. Ricardo argumenta que las dificultades que se presentan en términos disciplinarios en el aula se dan en muchas ocasiones cuando los niños provienen de familias con problemas, por ejemplo con un padre alcohólico, pues el niño ve eso y es un mal ejemplo. Doris dice que eso es un problema importante y que el profesor tiene que saberlo para llevar bien a ese niño. Ricardo continúa: "O cuando los padres no están en casa, porque los niños pasan más tiempo solos", y Leticia agrega: "Pegados todo el día a la tele sin hacer sus deberes". Luis toma notas de lo dicho por sus compañeros y pide que repitan algunas ideas para ordenarlas en la hoja. (24 de septiembre de 2012)

Los comentarios vertidos por los alumnos mientras realizaban la actividad descrita en la anterior cita etnográfica advierten del peligro que conlleva el que se ponga el acento en el incumplimiento del rol que se asigna a las familias cuando se trata de dar sentido a los problemas (académicos o disciplinarios) de los niños/as, máxime cuando el cumplimento de ese rol se entiende principalmente como una promoción de buenos modales que faciliten una dinámica escolar acorde con la labor del profesorado. El peligro al que me refiero consiste en que con comentarios como los mencionados se sientan las bases de prenociones que pueden orientar el ejercicio profesional de los alumnos una vez inicien su carrera docente. Las frases que, sobre este tema, se instalan en las clases son: "las familias son las responsables", "la educación fracasa por el distanciamiento de las familias con respecto a la escuela" o "las familias han abdicado", entre otras. Todo ello en su conjunto, como se ha dicho, contribuye a la configuración de una imagen de las familias que probablemente incida en el tipo de relación que los futuros maestros de educación primaria establezcan con ellas. Imagen que también se puede apreciar en el siguiente fragmento del diario de campo:

\section{Registro 6: Observación con notas de campo. Grupo 1.}

Contexto de las prácticas observadas: Es la primera exposición de grupo en la que se aborda el tema de "la educación en valores cívicos". Prácticas observadas: Una chica integrante del grupo plantea que los esfuerzos realizados por los docentes en materia de valores suelen perderse en las familias. (24 de octubre de 2012)

Llama la atención en la anterior cita etnográfica que, en las clases dirigidas a la formación de los futuros maestros en educación primaria, se hagan aseveraciones sobre las familias de los niños, como la de "los esfuerzos realizados por los docentes en materia 
de valores suele perderse en las familias", como si aludieran a evidencias incontrovertibles y que, quizá por ello, no son cuestionadas, dándose por sentada una realidad que no se sustenta ni, como se ha comentado ya, busca sustentarse en información contrastada de carácter empírico.

¿En qué se concreta, podríamos preguntarnos ahora, ese rol que se asigna a los padres con relación a la educación escolar de los hijos? Como se ha visto a lo largo de este artículo, se concreta y define desde el espacio escolar y en función de los objetivos escolares. Un rol que, en lo que se refiere a la participación de los padres en la escuela, consiste básicamente en ser informados por ésta, de modo que no suele sobrepasar el nivel informativo (Pereda, 2006) y cuya expresión más común se plasma, como ya se ha dicho, en prácticas como la asistencia a las reuniones trimestrales, a las tutorías individuales, $\mathrm{o}$ el apoyo en los deberes escolares que se envían a casa, apoyo que es muy valorado por los maestros, quizá porque supone una escasa o nula intromisión de las familias en el quehacer docente.

Otros elementos que contribuyen a configurar la imagen que los alumnos manejan sobre las familias son las opiniones de los maestros en ejercicio. Así, el segundo grupo de estudiantes que abordó el tema de la "educación en valores cívicos" dentro de la clase dirigida por Trinidad realizó visitas a los centros escolares para indagar acerca de lo que titularon: "interiorización de valores por parte de alumnos de $1^{\circ}$ y $6^{\circ}$ de primaria". Estos alumnos se encontraron con comentarios sobre el papel de las familias, emitidos por algunas maestras en ejercicio, como los recogidos en la cita etnográfica que se expone a continuación:

\section{Registro 7: Observación con notas de campo. Grupo 1.}

Contexto de las prácticas observadas: El grupo que expone presenta unos fragmentos de entrevistas realizadas a profesoras de educación primaria que desarrollan su carrera docente en colegios públicos. Prácticas observadas: Una de las chicas del grupo dice que ahora escucharemos unos fragmentos de las entrevistas que realizaron a profesoras de diferentes colegios. Comienza con una de las profesoras entrevistadas que trabaja en un colegio público, quien dice que en el colegio y en sus clases trabaja diferentes valores, pero en especial el de igualdad. Ella pone un ejemplo diciendo que fomenta la igualdad y el respeto por las diferentes culturas, porque tiene varios niñas y niños musulmanes en su aula, pero cuando los niños españoles llegan a sus casas, sus padres se 
refieren a los musulmanes como "moros de mierda". Por ello afirma que sus esfuerzos no sirven de nada. Otra profesora, también de colegio público, dice que ella va cambiando a sus alumnos de lugar en el aula cada cierto tiempo para que todos compartan y se relacionen, pero en ocasiones han llegado padres a reclamarle por eso porque no quieren que sus hijos se junten con otros compañeros que no sean españoles. Terminada la presentación de estos fragmentos de entrevistas, una de las integrantes del grupo comenta que los esfuerzos de las profesoras por trabajar en valores resultaban en vano, porque luego las familias no los cultivaban en el hogar. Trinidad interviene y dice: “¡Veis lo importante de hacer trabajo de campo!”. (25 de octubre de 2012)

El acercamiento que los alumnos realizan a las escuelas durante su proceso de formación inicial les permite relacionarse con profesores que han iniciado la (o tienen ya una larga) carrera docente y que, al tener una imagen negativa de las familias en lo que atañe a cómo educan a sus hijos/as, les transmiten y/o refuerzan, consciente o inconscientemente, esa imagen sobre las mismas. Fijémonos, además, en que en el anterior fragmento de diario de campo, cuando las integrantes del grupo repiten los comentarios sobre las familias hechos por las maestras en ejercicio, la profesora destaca la importancia del trabajo de campo. Ello pone en evidencia su acuerdo con lo dicho por ellas acerca de la existencia de discontinuidad o de desajuste entre la familia y la escuela en lo que se refiere, al menos en este caso, a los valores que cada una inculca o trata de inculcar a los niños/as en escenarios donde convive población autóctona con población extranjera.

Este entramado ideológico, que se articula en torno a una determinada concepción de la relación familia-escuela, favorece la externalización de responsabilidades que acontece cuando los niños no responden a las expectativas (académicas o disciplinarias) de la escuela, en la medida en que aporta elementos de verosimilitud a los discursos que vehiculan dicha externalización ${ }^{3}$. En efecto, si los niños defraudan las expectativas académicas, siempre cabe atribuirlo a que las familias no apoyan el trabajo de los profesores -máxime cuando estas son de origen extranjero-, y si las defraudadas son las expectativas disciplinarias, la responsabilidad puede hacerse recaer también en ellas por no cumplir con el trabajo que les compete.

\section{Conclusiones}

3 Véase en Jociles (2005) e Ibáñez (1979) un abordaje de la verosimilitud y de sus distintas modalidades ("referencial", "lógica", "poética", "tópica") como herramientas básicas para el análisis del discurso. 
Los alumnos asignan un rol educativo a las familias que es posible reconocer en sus discursos cuando, por ejemplo, demandan que éstas acompañen a los hijos para el logro de los objetivos de cada curso y nivel escolar, pero a la vez delimitan este acompañamiento en función de los intereses y los puntos de vista del profesorado. Esto podría entenderse por el hecho de que el profesorado se siente hoy en día amenazado, devaluado, lo que le habría llevado a procurar establecer alianzas de naturaleza instrumental con las familias, mediante las cuales les solicita apoyo y participación para el cumplimiento de los objetivos escolares, pero siempre que ello no suponga una intromisión y/o un cuestionamiento de sus competencias profesionales o, dicho en otros términos, siempre que no vean amenazada su autoridad como expertos en educación. Por tanto, las teorías implícitas que los alumnos manejan con respecto a la participación de las familias en la escuela muestran una concepción de la relación entre ambas instituciones que, siguiendo la tipología de Epstein (1995), puede ser calificada de instrumental pues se sitúan en el plano de la formalidad, a través de la colaboración en tareas asignadas desde la escuela, la asistencia a tutorías programadas por el profesorado. Dicho de otro modo, el acento está depositado en la 'legitimación' -por parte de los futuros titulados en maestro de primaria- del tipo de participación de carácter informativo. Todo ocurre como si temieran que una participación más profunda y activa de las familias supusiera un paso más en el desprestigio profesional de los docentes y, como se ha dicho, una amenaza para la "buena toma de decisiones", que no es otra que la que acude al criterio de los expertos.

Como indica Garreta (2008), las imágenes que los alumnos tienen de la relación familia-escuela son abordadas discursivamente desde la perspectiva de los vínculos interpersonales y no desde una perspectiva institucional, cultural u organizacional. Por otro lado, ha de plantearse que la formación inicial del profesorado se ocupa más de los aspectos técnico-pedagógicos implicados en los procesos de enseñanza-aprendizaje que de la formación de profesionales con capacidad crítica para la mejora del sistema educativo. Por ello los análisis de carácter macro-estructural se relegan a un segundo plano y adquiere prioridad atender a la relación directa con el alumnado con el fin de crear un clima que favorezca el aprendizaje y, en el ámbito de las relaciones familia-escuela, pensar en estrategias que lleven a una participación de los padres en los asuntos de la escuela que se mantenga dentro de los límites marcados por ésta y contribuya al logro por parte de los alumnos de los objetivos escolares.

Finalmente, teniendo en cuenta las entrevistas y las observaciones realizadas en aula, no es difícil extraer que la formación inicial del profesorado contribuye a construir, no a deconstruir, las prenociones que estos estudiantes tienen acerca del rol que desempeñan las familias y del que deben desempeñar en la educación escolar de los hijos. Así 
también, el hecho de que la mayoría de ellos destaque las tareas de apoyo escolar que las familias deben realizar desde sus casas sobre las que conllevan la entrada en el espacio de la escuela, puede ser interpretado como una respuesta a la necesidad que tiene ésta de establecer una lógica de continuidad entre ambas instituciones que se dirige a asegurar el éxito escolar de los niños, pero en unas condiciones que aseguran que el control permanezca en sus manos. De modo tal que lo que prevalece es la importancia atribuida a los invited spaces y no a los popular spaces; es decir, las familias han de participar en las formas, momentos y espacios que la escuela -y por ende, el profesorado- defina y estipule.

\section{Referencias}

Bolívar, A. (2006). Familia y escuela: dos mundos llamados a trabajar en común. Revista de Educación, 339, 97-118.

Cerletti, L. (2010). Familias y Escuelas: aportes de una investigación etnográfica a la problematización de supuestos en torno a las condiciones de escolarización infantil y la categoría familia. Intersecciones en Antropología, 11 (1), 185-198.

Cornwall, A. (2002). Making spaces, changing places: situating participation in development. IDS Working Paper, 170, 1-44.

Consejería de Asuntos Sociales. Comunidad de Madrid. (2013). Informe de población extranjera. Recuperado de http://www.madrid.org/cs/

Cucalon, P. (2012). Transitar en los límites de la escuela. Prácticas y representaciones de los profesores y alumnos de las Aula de Enlace. Etnia-e, 3, 1-113.

Del Olmo, M. (2005). Prejuicios y estereotipos: un replanteamiento de su uso y su utilidad como mecanismos sociales. XXI, Revista de Educación, 7, 13-23.

Epstein, J. (1995). School, family, community partnerships: caring for the children we share. Phi Delta Kappan, 76 (9).

Feito, R. (2010). Familias y escuela. Las razones de un desencuentro. Revista Educación y Futuro, 22, 701-712. 
Fernández, M. (2007). Educar es cosa de todos: escuela, familia y comunidad. En J. Garreta (ed.), La relación familia-escuela (pp. 13-32). Lleida, España: Ediciones Universidad de Lleida.

Franzé, A. (2001). Lo que sabía no valía. Escuela, diversidad e inmigración. Comunidad de Madrid. Madrid, España: Editorial Consejo Económico y Social.

García, F., Rubio, M. y Bouchra, O. (2008). Población inmigrante y escuela en España: un balance de investigación. Revista de Educación, 345, 23-60.

Garreta, J. (2007). La relación familia-escuela: ¿una cuestión pendiente? En J. Garreta (ed.), La relación familia-escuela (pp. 9-12). Lleida, España: Ediciones Universidad de Lleida.

-_-_. (2008). La participación de las familias en la escuela pública. Las asociaciones de madres y padres del alumnado. Madrid, España: Editores Centro de Investigación y Documentación Educativa (CIDE) y Confederación Española de Asociaciones de Padres y Madres de Alumnos (CEAPA).

- _- - (2009). Escuela y familias inmigradas: relaciones complejas. Revista Complutense de Educación, 20 (2), 275-291.

Gaventa, J. (2005). Reflections of the uses of the 'power cube' approach for analyzing the spaces, places and dynamics of civil society participation and engagement. CFP Evaluation Series (2003-2004), 4. Brighton, Inglaterra: Institute of Development Studies. University of Sussex.

Gil, I. (2009). Diversidad cultural en educación obligatoria. ¿Qué sucede en las escuelas? En M. Fernández y W. Müllauer-Seichter (eds.), La integración escolar a debate (pp. 143169). Madrid, España: Pearson Prentice Hall.

Gubbins, V. (2012). Familia y Escuela: tensiones, reflexiones y propuestas. Docencia, 46, 6473.

Ibáñez, J. (1979). Más allá de la sociología. El grupo de discusión: teoría y crítica. Madrid, España: Editorial Siglo XXI.

Jociles, M. (2002). Contexto etnográfico y uso de las técnicas de investigación social. En I. De la Cruz (ed.), Introducción a la antropología para la intervención social (pp.85-119). Valencia, España: Ediciones Tirant Lo Blanch. 
————. (2005). El análisis del discurso: de cómo utilizar desde la antropología social la propuesta analítica de Jesús Ibáñez. Avá. Revista de Antropología, 7, 1-25.

Jociles, M., Franzé, A. y Poveda, D. (2012). La diversidad cultural como problema: representaciones y prácticas escolares con adolescentes de origen latinoamericano en Madrid. Revista Alteridades, 22 (43), 63-78.

Marchesi, A. (2000). Controversias en la educación española. Madrid, España: Editorial Alianza.

Marina, J. (2006). Familia y educación. En M. López (ed.), La familia en el proceso educativo (pp. 223-246). Madrid, España: Ediciones Cinca.

Martín, E. y Coll, C. (2003). Aprender contenidos, desarrollar capacidades. Intenciones educativas y planificación de la enseñanza. Barcelona, España: Editorial Edebé.

Moscoso, M. (2009). Perspectivas de padres y madres ecuatorianos sobre el contrato pedagógico entre la institución escolar y la familia en un contexto migratorio. Revista Papeles de Trabajo sobre Cultura, Educación y Desarrollo Humano, 5 (1). Recuperado de http:// www.uam.es/otros/ptcedh/2009v5_pdf/v5n1esp.pdf

Neufeld, M. (2000). Familias y Escuelas: la perspectiva de la antropología social. Ensayos y Experiencias, 36, 3-13.

Osuna, C. (2012). En torno a la educación intercultural. Una revisión crítica. Revista de Educación, 358, 38-58.

Pereda, V. (2006). La participación de las familias en los centros educativos. Algunos pasos dados. Mucho camino por recorrer. En M. López (ed.), La familia en el proceso educativo (pp. 13-50). Madrid, España: Ediciones Cinca.

Pozo, J. (1996). Aprendices y maestros. Madrid, España: Editorial Alianza.

Poveda, D., Jociles, M. y Franze, A. (2009). La diversidad cultural en la educación secundaria en Madrid: experiencias y prácticas institucionales con alumnado latinoamericano. Revista Papeles de Trabajo sobre Cultura, Educación y Desarrollo Humano, 5 (3).

Río, M. (2010). No quieren, no saben, no pueden: categorizaciones sobre las familias más alejadas del campo escolar. Revista Española de Sociología (RES), 14, 85-105. 
Roldán, M. (2008). Familia y escuela como agentes de socialización. En M. López (ed.), Familia, escuela y sociedad. Responsabilidades compartidas en la educación (pp. 95-137). Madrid, España: Ediciones Cinca.

Santín, D. (2006). Familia, escuela y fracaso escolar. En M. López (ed.), La familia en el proceso educativo (pp. 181-222). Madrid, España: Ediciones Cinca.

Santos Guerra, M. (1997). El crisol de la participación. Investigación sobre la participación en Consejos Escolares de centros. Archidona, España: Editorial Aljibe.

- _- . (2010). La formación del profesorado en las instituciones que aprenden. Revista Interuniversitaria de formación del profesorado, 68 (24, 2), 175-200. 